\title{
East Asian climate under global warming: understanding and projection
}

\author{
Jianping $\mathrm{Li}^{1,2} \cdot$ Huang-Hsiung $\mathrm{Hsu}^{3} \cdot$ Wei-Chyung Wang ${ }^{4} \cdot \mathrm{Kyung}^{-J a ~} \mathrm{Ha}^{5} \cdot \mathrm{Tim}^{\mathrm{L}}{ }^{6} \cdot$ Akio Kitoh $^{7}$
}

Published online: 1 November 2018

c) Springer-Verlag GmbH Germany, part of Springer Nature 2018

This special issue of Climate Dynamics is devoted to the recent progress in investigations of East Asian climate (EAC) under global warming: Understanding and projection.

East Asia is located in the southeast part of the Eurasian continent. It is bordered on the east by the Pacific Ocean and on the southwest by the Tibetan Plateau (TP). The unique geographic features produce distinct climate characteristics over this region ( $\mathrm{Li}$ et al. 2011a, b), and EAC study is one of the foci of the Asian Monsoon Years (AMY 2007-2012) (Wang et al. 2010; Matsumoto et al. 2010), which is a coordinated observation and modeling effort under the leadership of the World Climate Research Programme (WCRP). A workshop was held on 18-20 October 1994 at the State University of New York at Albany to discuss this topic, and the participants agreed to embark a collaborative research project, "General Circulation Model (GCM) Simulations of the EAC". The project was subsequently listed as the Subproject \#25 in the Atmospheric Model Intercomparison Project (AMIP)-Coupled Model Intercomparison Project (CMIP)

Jianping Li

ljp@bnu.edu.cn

1 College of Global Change and Earth System Science, Beijing Normal University, Beijing 100875, China

2 Laboratory for Regional Oceanography and Numerical Modeling, Qingdao National Laboratory for Marine Science and Technology, Qingdao 266237, China

3 Research Center for Environmental Changes, Academia Sinica, 128 Academia Road, Section 2, Nankang, Taipei 115, China

4 Atmospheric Sciences Research Center, State University of New York at Albany, Albany, NY 12203, USA

5 Department of Atmospheric Sciences, Pusan National University, Busan 46241, South Korea

6 International Pacific Research Center, and Department of Atmospheric Sciences, School of Ocean and Earth Science and Technology, University of Hawaii, Hawaii 96822, USA

7 Meteorological Business Support Center, Meteorological Research Institute, Tsukuba, Ibaraki 305-0052, Japan in 1994 with Profs. Wei-Chyung Wang and Guoxiong Wu as the Coordinators; and Yihui Ding, Huang-Hsiung Hsu, Akio Kitoh, and Jeong-Woo Kim as members. From 2008 to 2009, Profs. Huang-Hsiung Hsu and Bin Wang are the EAC Coordinators. Since 2009 Profs. Huang-Hsiung Hsu and Jianping Li have become the EAC Coordinators, and there are 12 members. The project has three main objectives as follows:

i. To study the mechanisms and impacts of the EAC variability, especially for some extreme events;

ii. To understand the change of the EAC variability under global warming;

iii. To assess the technique of detection and the ability of current GCMs in simulating the EAC, and to discuss the predictability of the EAC.

Almost every 2 years, the EAC committee organizes an international workshop to present and discuss collaborative research progress in EAC study. Over the years, thirteen workshops were already organized and the latest one in Beijing, China on 24-25 March, 2016. The EAC 2016 workshop attracted about 100 participants from 7 countries or regions. The special collection includes papers studying the foci of EAC and reporting the latest advances in the aspects as follows: Detection and attribution; Climate variability; Highimpact weather and extremes; and Predictability, prediction and projection.

Some important results come from the EAC 2016 workshop include:

- An out-of-phase rainfall variation is found over central Asia and northern China in the upper-level Asian westerly jet (AWJ) region in the interannual timescale, and is closely related to the southeast-northwest shift of AWJ.

- The increases in sea surface temperature (SST) and atmospheric heating over Southeast Asia result in a dry- 
ing southern China in spring, and a drying South Asia and Sahel regions in summer.

- The intraseasonal SST variations in the South China Sea (SCS) display a close association with the East Asian winter monsoon (EAWM) change with a time lag of 3-5 days.

- Some new modulators for Asian monsoon variability are introduced, e.g., IPOD (a cross-basin dipole pattern of SSTA variability between the Indo-Pacific warm pool (IPWP) and North Pacific Ocean), IPCO (Indo-Western Pacific convection oscillation), the warmest SST axis in the Bay of Bengal (BoB) and monsoon onset, synergistic effects of extratropical and tropical systems.

- Relative contributions of the TP thermal forcing and the Indian Ocean SST basin mode to the interannual variability of the East Asian summer monsoon (EASM) were discussed.

- Characteristics of SCS SST associated with ENSO shows interdecadal variability.

- Interannual and decadal variations of South Asian High (SAH) and UTTM intensity are strongly affected by EASM condensation over the eastern TP-Yangtze River Valley.

- The Asian summer monsoon is thermally controlled by both land-sea distribution and the presence of the Tibetan-Iranian Plateau (TIP).

- Coherent evidences suggest the recent intensification of the covariability between North Pacific subtropical high (NPSH) and western NPSH (WNPSH) along with considerable decadal variabilities.

- The WNP (western North Pacific) and CP (central Pacific) precipitation anomalies associated with ENSO have opposite effects on teleconnection patterns over North Pacific and East Asia.

- The change of El Niño behavior since 1999 is likely attributed to the interdecadal mean state change in the tropical Pacific. Global warming effect appears weak.

- The increase in anthropogenic emissions over East Asia may play a role in compensating for the weakening of the EASM caused by the SST forcing.

- The TP snow cover can influence the interannual variations of Eurasian heat wave frequency.

- The anthropogenic forcing has a detectable and attributable influence on the amount distribution of daily precipitation over Eastern China during the second half of the twentieth century.

- Long-term change of extreme daily precipitation over a 100 years in Japan shows increase in heavy precipitation and decrease in weak precipitation.

- Maximum 1-h rainfall for megacities (Shanghai and Guangzhou) has increased in recent $60-100$ years. The increasing 1-h rainfall intensity is caused by both climate change and urbanization effects.
- The North American dipole (NAD) is closely related to the CP-type El Niño a year later.

- While in the subtropical domain of the WNP-EASM, the MME probabilistic skill improvement seems to be mainly due to the increase in ensemble size, in the tropical domain a significant component of the improvement comes from the model diversity inherent in the MME approach.

- An intra-seasonal view of monsoon onset over BoB is proposed, i.e., eastward MJO transit to first northward propagating ISO, triggered by central BoB warming.

- The increase of temperature and change in precipitation patterns lead to an increase in global aridity and expansion of global drylands.

- Two dominant global-scale teleconnections in the Northern Hemisphere extratropics during boreal summer were identified: the western North Pacific-North America (WPNA) and circumglobal teleconnection (CGT) patterns.

This special issue comprises 40 peer-reviewed papers, which is divided into four parts as follows. Part I, detection and attribution, which contains 13 papers, discusses responses of rainfall and circulations in summer over East Asia to anthropogenic aerosol climate forcing and global warming (Chen et al. 2018a, b; Kim and Ha 2018), analyses stratospheric impacts on East Asian winter climate (Wei et al. 2018) and spring precipitation in China (Xie et al. 2018) and effects of the Indo-Pacific warm pool on the stratosphere (Zhou et al. 2018), explores influences of regional and global SST anomaly (Han et al. 2018; Liu and Duan 2018), the Southern Hemisphere annular mode (SAM) and East Asian westerly jet on EAC (Liu et al. 2018; Wang et al. 2018a, b; Hu et al. 2018a, b), and detects hydrological processes over the TP and East Asia (Guo et al. 2018a; Meng et al. 2018).

Part II, Climate variability, which includes 13 papers, investigates intraseasonal oscillations and their impacts on seasonal mean SST (Wu 2018; Krishnamurthy 2018), explores linkages of EAC with South Asian summer monsoon and North Atlantic Oscillation (NAO) (Ha et al. 2018; Feng et al. 2018), analyses variability of water vapor transport associated with EAC (Li et al. 2018; Leung et al. 2018; Chen et al. 2018c; Wu et al. 2018), and discusses impacts of ENSO and its types, thermodynamic and dynamic responses to SST forcing associated with El Niño (Chen and Li 2018; Hu et al. 2018a, b; Kim et al. 2018), types of Indian Ocean Basin modes (Guo et al. 2018b) as well as decadal-scale variability of surface temperature over East Asia (Chen et al. 2018d).

Part III, High-impact weather and extremes, which is composed of 6 papers, analyses extreme precipitation over Japan (Nayak et al. 2018) and heat waves over the Yangtze 
River valley (Chen and Zhou 2018; Gao et al. 2018), studies variability of spring dust weather in North China (Fan et al. 2018) and subseasonal shift in tropical cyclone genesis (Choi and Ha 2018), and discusses influences of extreme events on crop yield (Wang et al. 2018a, b).

Part IV, Modelling, predictability, prediction and projection, which consists of 8 papers, makes comparison of the global atmospheric model MRI-AGCM3.2 and the CMIP5 atmospheric models in simulating precipitation over East Asia (Kusunoki 2018a), discusses simulation biases of ENSO forced and local variability of North Tropical Atlantic SST (Yang et al. 2018) and the role of horizontal resolution over the TP in the REMO regional climate model (Xu et al. 2018), explores predictability of summer extreme precipitation days over eastern China (Li and Wang 2018) and predictability of two types of El Niño in coupled models (Lee et al. 2018), studies statistical model of interannual variability of the EAWM (Yu et al. 2018) and statistically seasonal prediction of the typhoon genesis frequency over the Western North Pacific (Zhang et al. 2018), and projects future changes in precipitation over East Asia (Kusunoki 2018b)

It is the editors' sincere hope that this special issue may contribute to relevant studies in EAC.

Acknowledgements We wish to thank the contributors and the referees of this special collection, EAC committee members, Ms. Xiaoxi $\mathrm{Li}$ and Springer, and supports from the International Commission on Climate (ICCL) of IAMAS (International Association of Meteorology and Atmospheric Sciences), IUGG (International Union of Geodesy and Geophysics) Union-Commission on Climatic and Environmental Change (CCEC), and National Natural Science Foundation of China (NSFC). This work was jointly supported by the State Oceanic Administration (SOA) International Cooperation Program on Global Change and Air-Sea Interactions (GASI-IPOVAI-03) and National Natural Science Foundation of China (NSFC) Project (41530424).

\section{References}

Chen MC, Li T (2018) Why 1986 El Niño and 2005 La Niña evolved different from a typical El Niño and La Niña? Clim Dyn. https:// doi.org/10.1007/s00382-017-3852-1

Chen X, Zhou TJ (2018) Relative contributions of external SST forcing and internal atmospheric variability to July-August heat waves over the Yangtze River valley. Clim Dyn. https://doi.org/10.1007/ s00382-017-3871-y

Chen GX, Wang WC, Chen JP (2018a) Circulation responses to regional aerosol climate forcing in summer over East Asia. Clim Dyn. https://doi.org/10.1007/s00382-018-4267-3

Chen GX, Yang J, Bao Q, Wang WC (2018b) Intraseasonal responses of the East Asia summer rainfall to anthropogenic aerosol climate forcing. Clim Dyn. https://doi.org/10.1007/s00382-017-3691-0

Chen B, Xu XD, Zhao TL (2018c) Quantifying oceanic moisture exports to mainland China in association with summer precipitation. Clim Dyn. https://doi.org/10.1007/s00382-017-3925-1
Chen JW, Deng Y, Lin WS, Yang S (2018d) A process-based decomposition of decadal-scale surface temperature evolutions over East Asia. Clim Dyn. https://doi.org/10.1007/s0038 2-017-3872-x

Choi Y, Ha KJ (2018) Subseasonal shift in tropical cyclone genesis over the western North Pacific in 2013. Clim Dyn. https://doi. org/10.1007/s00382-017-3926-0

Fan K, Xie ZM, Wang HJ, Xu ZQ, Liu JP (2018) Frequency of spring dust weather in North China linked to sea ice variability in the Barents Sea. Clim Dyn. https://doi.org/10.1007/s0038 2-016-3515-7

Feng GL, Zou M, Qiao SB, Zhi R, Gong ZQ (2018) The changing relationship between the December North Atlantic Oscillation and the following February East Asian trough before and after the late 1980s. Clim Dyn. https://doi.org/10.1007/s00382-018-4165-8

Gao M, Yang J, Wang B, Zhou SY, Gong DY, Kim SJ (2018) How are heat waves over Yangtze River valley associated with atmospheric quasi-biweekly oscillation? Clim Dyn. https://doi.org/10.1007/ s00382-017-3526-Z

Guo L, Klingaman NP, Demory ME, Vidale PL, Turner AG, Stephan CC (2018a) The contributions of local and remote atmospheric moisture fluxes to East Asian precipitation and its variability. Clim Dyn. https://doi.org/10.1007/s00382-017-4064-4

Guo FY, Liu QY, Yang JL, Fan L (2018b) Three types of Indian Ocean Basin modes. Clim Dyn. https://doi.org/10.1007/s0038 2-017-3676-Z

Han TT, He SP, Wang HJ, Hao X (2018) Enhanced influence of earlyspring tropical Indian Ocean SST on the following early-summer precipitation over Northeast China. Clim Dyn. https://doi. org/10.1007/s00382-017-3669-y

Hu KM, Huang G, Wu RG, Wang L (2018a) Structure and dynamics of a wave train along the wintertime Asian jet and its impact on East Asian climate. Clim Dyn. https://doi.org/10.1007/s0038 2-017-3674-1

Hu XM, Cai M, Yang S, Wu ZH (2018b) Delineation of thermodynamic and dynamic responses to sea surface temperature forcing associated with El Niño. Clim Dyn. https://doi.org/10.1007/s0038 2-017-3711-0

Kim BH, Ha KJ (2018) Changes in equatorial zonal circulations and precipitation in the context of the global warming and natural modes. Clim Dyn. https://doi.org/10.1007/s00382-017-3819-2

Kim SY, Hye-Young Son HY, Kug JS (2018) Relative roles of equatorial central Pacific and western North Pacific precipitation anomalies in ENSO teleconnection over the North Pacific. Clim Dyn. https://doi.org/10.1007/s00382-017-3779-6

Krishnamurthy V (2018) Intraseasonal oscillations in East Asian and South Asian monsoons. Clim Dyn. https://doi.org/10.1007/s0038 2-016-3466-Z

Kusunoki S (2018a) Is the global atmospheric model MRI-AGCM3.2 better than the CMIP5 atmospheric models in simulating precipitation over East Asia?. Clim Dyn. https://doi.org/10.1007/s0038 2-016-3335-9

Kusunoki S (2018b) Future changes in precipitation over East Asia projected by the global atmospheric model MRI-AGCM3.2. Clim Dyn. https://doi.org/10.1007/s00382-016-3499-3

Ha KJ, Seo YW, Lee JY, Kripalani RH, Yun KS (2018) Linkages between the South and East Asian summer monsoons: a review and revisit. Clim Dyn. https://doi.org/10.1007/s00382-017-3773-z

Lee RWK, Tam CY, Sohn SJ, Ahn JB (2018) Predictability of two types of El Niño and their climate impacts in boreal spring to summer in coupled models. Clim Dyn. https://doi.org/10.1007/ s00382-017-4039-5

Leung MYT, Qiu S, Zhou W (2018) Modulations of rising motion and moisture on summer precipitation over the middle and lower reaches of the Yangtze River. Clim Dyn. https://doi.org/10.1007/ s00382-018-4247-7 
Li J, Wang B (2018) Predictability of summer extreme precipitation days over eastern China. Clim Dyn. https://doi.org/10.1007/s0038 2-017-3848-x

Li JP, Wu GX, Hu DX et al (2011a) Ocean-atmosphere interaction over the joining area of Asia and Indian-Pacific Ocean and its impact on the short-term climate variation in China (volume I). China Meteorological Press, Beijing, pp 1-516

Li JP, Wu GX, Hu DX et al (2011b) Ocean-atmosphere interaction over the joining area of Asia and Indian-Pacific Ocean and its impact on the short-term climate variation in China (volume II). China Meteorological Press, Beijing, pp 517-1081

Li PX, Zhou TJ, Chen XL (2018) Water vapor transport for spring persistent rains over southeastern China based on five reanalysis datasets. Clim Dyn. https://doi.org/10.1007/s00382-017-3680-3

Liu SF, Duan AM (2018) Impacts of the global sea surface temperature anomaly on the evolution of circulation and precipitation in East Asia on a quasi-quadrennial cycle. Clim Dyn. https://doi. org/10.1007/s00382-017-3663-4

Liu T, Li JP, Li YJ, Zhao S, Zheng F, Zheng JY, Yao ZX (2018) Influence of the May Southern annular mode on the South China Sea summer monsoon. Clim Dyn. https://doi.org/10.1007/s0038 2-017-3753-3

Matsumoto J, Wang B, Li JP, Wu GX (2010) The Implementation Plan for Asian Monsoon Years (AMY 2007-2012). China Meteorological Press, Beijing, 38 pp

Meng X, Li R, Luan L, Lyu S, Zhang T, Ao Y, Han B, Zhao L, Ma Y (2018) Detecting hydrological consistency between soil moisture and precipitation and changes of soil moisture in summer over the Tibetan Plateau. Clim Dyn. https://doi.org/10.1007/s0038 2-017-3646-5

Nayak S, Dairaku K, Takayabu L, Suzuki-Parker A, Ishizaki N (2018) Extreme precipitation linked to temperature over Japan: current evaluation and projected changes with multi-model ensemble downscaling. Clim Dyn. https://doi.org/10.1007/s0038 2-017-3866-8

Wang B, Matsumoto J, Wu GX, Li JP (2010) The Science Plan for Asian Monsoon Years (AMY 2007-2012). China Meteorological Press, Beijing, $67 \mathrm{pp}$

Wang SX, Zuo HC, Zhao SM, Zhang JK, Lu S (2018a) How East Asian westerly jet's meridional position affects the summer rainfall in
Yangtze-Huaihe River Valley? Clim Dyn. https://doi.org/10.1007/ s00382-017-3591-3

Wang Z, Shi PJ, Zhang Z, Meng YC, Luan YB, Wang JW (2018b) Separating out the influence of climatic trend, fluctuations, and extreme events on crop yield: a case study in Hunan Province, China. Clim Dyn. https://doi.org/10.1007/s00382-017-3831-6

Wei K, Cai ZL, Chen W, Xu LY (2018) The effect of a well-resolved stratosphere on East Asian winter climate. Clim Dyn. https://doi. org/10.1007/s00382-016-3419-6

Wu R (2018) Feedback of 10-20-day intraseasonal oscillations on seasonal mean SST in the tropical Western North Pacific during boreal spring through fall. Clim Dyn. https://doi.org/10.1007/ s00382-016-3362-6

Wu Y, Huang AN, Huang DQ, Chen F, Yang B, Zhou Y, Fang DX, Zhang LJ, Wen LJ (2018) Diurnal variations of summer precipitation over the regions east to Tibetan Plateau. Clim Dyn. https:// doi.org/10.1007/s00382-017-4042-x

Xie F, Ma X, Li JP, Huang JL, Tian WS, Zhang JK, Hu YY, Sun C, Zhou X, Feng J, Yang Y (2018) An advanced impact of Arctic stratospheric ozone changes on spring precipitation in China. Clim Dyn. https://doi.org/10.1007/s00382-018-4402-1

Xu JW, Koldunov N, Remedio ARC, Sein DV, Zhi XF, Jiang X, Xu M, Zhu XH, Fraedrich K, Jacob D (2018) On the role of horizontal resolution over the Tibetan Plateau in the REMO regional climate model. Clim Dyn. https://doi.org/10.1007/s00382-018-4085-7

Yang Y, Xie SP, Wu LX, Kosaka Y, Li JP (2018) ENSO forced and local variability of North Tropical Atlantic SST: model simulations and biases. Clim Dyn. https://doi.org/10.1007/s0038 2-017-3679-9

Yu LL, Wu ZW, Zhang RH, Yang X (2018) Partial least regression approach to forecast the East Asian winter monsoon using Eurasian snow cover and sea surface temperature. Clim Dyn. https:// doi.org/10.1007/s00382-017-3757-z

Zhang XC, Zhong SS, Wu ZW, Li Y (2018) Seasonal prediction of the typhoon genesis frequency over the Western North Pacific with a Poisson regression model. Clim Dyn. https://doi.org/10.1007/ s00382-017-3654-5

Zhou X, Li JP, Xie F, Ding RQ, Li YJ, Zhao S, Zhang JK, Li Y (2018) The effects of the Indo-Pacific warm pool on the stratosphere. Clim Dyn. https://doi.org/10.1007/s00382-017-3584-2 